\title{
Coronary steal phenomenon following right ventricle decompression and revascularization of atretic left coronary ostium - case report
}

Jacek Pająk

Medical University of Warsaw: Warszawski Uniwersytet Medyczny

Maciej Aleksander Karolczak

Medical University of Warsaw: Warszawski Uniwersytet Medyczny

Michał Buczyński

Medical University of Warsaw: Warszawski Uniwersytet Medyczny

Wojciech Mądry

Medical University of Warsaw: Warszawski Uniwersytet Medyczny

Darren James Grégoire

Medical University of Warsaw: Warszawski Uniwersytet Medyczny

Piotr Weryński

Uniwersytet Jagiellonski Collegium Medicum Wydzial Lekarski

Wanda Król - Jawień

Uniwersytet Jagiellonski w Krakowie Collegium Medicum

Krzysztof Godlewski

Medical University of Warsaw: Warszawski Uniwersytet Medyczny

Lidia Tomkiewicz - Pająk

Uniwersytet Jagiellonski w Krakowie Collegium Medicum

Jacek Kuźma ( $\sim$ kuzmajacek@yahoo.com )

Warsaw University Hospital: Samodzielny Publiczny Centralny Szpital Kliniczny

https://orcid.org/0000-0002-0167-2680

\section{Case report}

Keywords: coronary artery atresia, coronary fistula, coronary revascularization, fistula embolization

Posted Date: June 21st, 2021

DOl: https://doi.org/10.21203/rs.3.rs-481291/v1

License: (a) (i) This work is licensed under a Creative Commons Attribution 4.0 International License. Read Full License 


\section{Abstract}

\section{Background}

Coronary steal phenomenon and myocardial ischemia is a complication following decompression of a hypertensive right ventricle in patients with left coronary-cameral fistulae.

\section{Case presentation}

We present a 12-year-old girl with a complex heart defect successfully operated on using a hybrid surgical-interventional approach to decompress the ventricle, embolize the fistula and reconstruct the atretic left coronary ostium.

Conclusions

A novel hybrid strategy is the best solution for coronary-cameral fistulas reliant on high ventricular pressure at high risk for coronary steal phenomenon.

\section{Introduction}

Atresia of the left coronary artery ostium (ALCAO) is one of the rarest congenital coronary anomalies, in which a solitary right coronary artery supplies the entire myocardium. The myocardium may receive additional perfusion via fistulas from hypertensive ventricles [1,2]. Unilateral coronary ostial atresia usually follows complex heart defects as in the presented case with pulmonary atresia causing critical stenosis with an intact ventricle septum and hypertensive right ventricle chamber. Patients with ALCAO and insufficient coronary perfusion may develop variable symptoms including chest pain, fatigue, dyspnea, arrhythmias, syncope, cardiac compromise and sudden cardiac death [3]. In most children with ALCAO the perioperative mortality is high, therefore heart transplant is the viable option $(4,5)$. We present a novel surgical-interventional hybrid alternative for successful restoration of anatomical and physiological coronary circulation complicated by myocardial ischemia due to coronary steal phenomenon.

\section{Patient Information}

A 12-year-old girl with severe pulmonary valvar stenosis (PVS), atretic left main coronary artery ostium (ALCAO) and a wide fistula between the hypertensive right ventricle (RV) and the left coronary artery received surgical follow-up consultation.

\section{Clinical Findings}

The child had NYHA class II-III, episodic abdominal pain and exertional dyspnea. Physical examination showed good general condition, regular heart rate of 70 beats/min, loud systolic murmur of $4-5 / 6$ on 
Levine scale with a thrill over the chest and jugular notch. Blood pressure was $100 / 60 \mathrm{mmHg}$, respiratory rate 14 breaths/min and $\mathrm{SaO}_{2} 96 \%$ on room air.

\section{Timeline}

The known heart defect was diagnosed at birth. Neonatal balloon pulmonary valvuloplasty permitted corrective surgery to be postponed. Heart transplant remained a viable option due to high clinical risk status and operation complexity. The patient attended for echocardiography for 12-year follow-up prior to admission to the cardiac surgery department.

\section{Diagnostic Assessment}

Normal sinus rhythm with right axis deviation and severe right ventricular hypertrophy were found on ECG. Roentgenogram showed cardiomegaly, pulmonary trunk dilatation and right atrium enlargement. TTE visualized $2^{\text {nd }}$ degree tricuspid valve regurgitation with pressure gradient of $138 \mathrm{mmHg}$, and PVS pressure gradient of $148 \mathrm{mmHg}$. Hemodynamic studies recorded increased central venous $(12 \mathrm{mmHg}), \mathrm{LV}$ end-diastolic (15mmHg) and suprasystemic RV pressures $(127 / 15 \mathrm{mmHg})$.

Angiographic studies illustrated wide RCA (5mm) and atretic ostium of the LMCA (Figure 1, Supplemental Video1). Right ventriculography outlined severe pulmonary valvar stenosis with dome-shaped valve leaflets and post-stenotic pulmonary trunk dilatation. Furthermore, selective fistula angiography and 3D rendered Computed Tomography depicted ALCAO and a wide coronary fistula emerging from the hypertrophic RV (Figures 2, 3; Supplemental Video 2, 3). The fistula orifice sat superficially in the anterior interventricular groove. Multiple proximal and distal converging collateral anastomoses were present between the LMCA and RCA. The LMCA divided into the left anterior descending artery (LAD) and the circumflex artery (CX).

\section{Therapeutic Intervention}

The patient was qualified for LMCA ostium reconstruction and simultaneous interventional fistula embolization. Sternotomy with cross-clamped aorta and cannulated caval veins under $24^{\circ} \mathrm{C}$ hypothermia on cardiopulmonary bypass supported the patient. The RCA cardioplegic solution infusion sustained electromechanical quiescence to asystole. Epicardial fat meant the fistula was not visible. The ascending aorta, bulb and proximal LMCA segment were precisely dissected. The ostium was atretic due to a fibrous diaphragm which was excised, and the artery reconstructed with a Biointegral patch. Next, a RVOT infundibulectomy was undertaken with pulmonary commissurotomy and partial resection of the dysplastic leaflets. The now reconstructed and patent LMCA ostium provided a conduit for a multipurpose 5-F catheter over a 0.025 -inch hydrophilic steerable guidewire. The fistula branches were implanted with two 6mm diameter Amplatzer Vascular Plugs II (St. Jude Medical, St Paul, MN). Intraoperative epicardial ECHO confirmed antegrade LMCA flow, normal myocardial contractility, and minor fistula leak. The cross-clamp was released and normal sinus rhythm without ischemic ECG changes emerged upon myocardial reperfusion. Post-operative hemodynamic catheterization revealed 
high RV systolic and diastolic pressures $(60 / 25 \mathrm{mmHg})$, LVEDP $(90 / 26 \mathrm{mmHg})$, central venous pressure $(25 \mathrm{mmHg})$, pulmonary venous hypertension (mean $30 \mathrm{mmHg}$ ) with increased pulmonary flow. Residual fistula leaks (Figure 4, Supplemental Video 4) required interventional endovascular embolization using multiple occluders which were redelivered via LMCA without sequalae (Figure 5, Supplemental Video 5).

\section{Follow-up and Outcomes}

At 2-year follow-up the girl was asymptomatic on pharmacotherapy (metoprolol and aspirin) with good exercise tolerance (NYHA II). Resting ECG showed normal sinus rhythm without symptoms of ischemia while $2 \mathrm{DE}$ revealed good EF (50\%) and sealed fistula.

\section{Discussion}

Ischemic ALCAO with cardiomyopathy is an indication for urgent surgery using a left internal mammary artery bypass graft, although in complex heart defects and small children heart transplant is considered a viable option. Our patient's resting ECG was not suggestive of ischemia as suprasystemic RV pressure and wide fistula patency secured left coronary flow despite ALCAO. Yet, upon reconstructing the LMCA ostium and decompressing the RV, coronary steal phenomenon and heart failure ensued. In small children, coronary ostium reconstruction with a patch offers an alternative solution [4]. In those with a coronary fistula, traditional surgical ligation is preferential to avoid myocardial ischemia [5]. However, the fistula orifice is difficult to visualize and precisely ligate. Patched coronary ostium reconstruction and simultaneous hybrid fistula embolization are viable procedures in anomalies technically difficult to approach. Our concerns about RV decompression and coronary steal phenomenon proved to be well founded as further embolization were needed for residual fistula leakage.

Critical considerations and limitations of the presented case include shortage of published literature and guidelines for children with coronary anomalies. Rigid surgical-only solutions proposed in the literature lack flexibility to adapt to individual cases which appears to be crucial. For instance, a pragmatic approach depends on body weight, coexisting heart defects, hemodynamic flow, and the surgeon's experience. In the presented case, the authors demonstrate the viability of a hybrid approach to complex coronary anomalies with high perioperative mortality to restore functional anatomy and physiology.

The learning objective recalls the risk of the coronary steal phenomenon appearing after hypertensive RV decompression - a key source of coronary perfusion in patients with cameral fistulas. Complex congenital coronary anomalies with technical difficulty ought to strongly consider a hybrid treatment with staged planning and close hemodynamic monitoring.

\section{Patient Perspective}

The patient shared an optimistic outlook toward attending high school despite restricted sports participation and pharmacotherapy. 
The family were grateful to the medical staff for the complex yet successful treatment which avoided heart transplant.

\section{Informed consent}

Informed consent to publish was obtained from the patient's mother.

\section{Abbreviations}

ALCAO - atresia of the left coronary artery ostium

$\mathrm{EF}$ - ejection fraction

LMCA - left main coronary artery

LV - left ventricle

LVEDP - left ventricle end-diastolic pressure

NYHA - New York Heart Association - functional classification of heart failure

RCA - right coronary artery

PVS - pulmonary valvar stenosis

$\mathrm{RV}$ - right ventricle

RVEDP - right ventricle end-diastolic pressure

TTE - transthoracic echocardiogram

\section{Declarations}

Ethics approval and consent to participate

Awaiting bioethics committee approval

Consent for publication

Informed consent to publish was obtained from the patient's mother.

Availability of data and materials

The data are available for public access.

Competing interests 
The authors declare that they have no competing interests.

Funding

The authors declare that this work is supported by the grant of Medical University of Warsaw.

Authors' contributions: JK, WKJ and KG diagnosed the patient. JP, MAK, MB, and PW performed the surgery. JK, WM, DJG and LTM were major contributors in writing the manuscript. All authors read and approved the final manuscript.

Acknowledgments

We thank the patient's parents for allowing us to present the treatment history. We also thank PhD M. Karolczak, head of the Department of Cardiac and General Pediatric Surgery for substantive guidance and supervision.

\section{References}

1. Hayashi T, Waki K, Arakaki Y. Left Main Coronary Artery Atresia in a Child: A Case Report and Review of the Literature. Cardiol Young. 2017;27(9):1841-4.

2. Hartz J, Nathan M, Newburger JW, Quinonez L. Surgical Repair of Congenital Atresia of the Left Coronary Ostium. JACC Case Reports. 2021;3:198-201.

3. D'Souza TF, Samuel BP, Vettukattil JJ, et al. Surgical treatment of neonate with congenital left main coronary artery atresia. Ann Thorac Surg. 2016;101:352-5.

4. Amaral F, Tanamati C, Granzotti JA, et al. Congenital atresia of the ostium of the left coronary artery. Diagnostic difficulty and successful surgical revascularization in two patients. Arq Bras Cardiol. 2000;74:339-42.

5. Kamiya $H$, Yasuda $T$, Nagamine $H$, et al. Surgical treatment of congenital coronary artery fistulas: 27 years' experience and a review of the literature. J Card Surg. 2002;17:173-7.

\section{Figures}




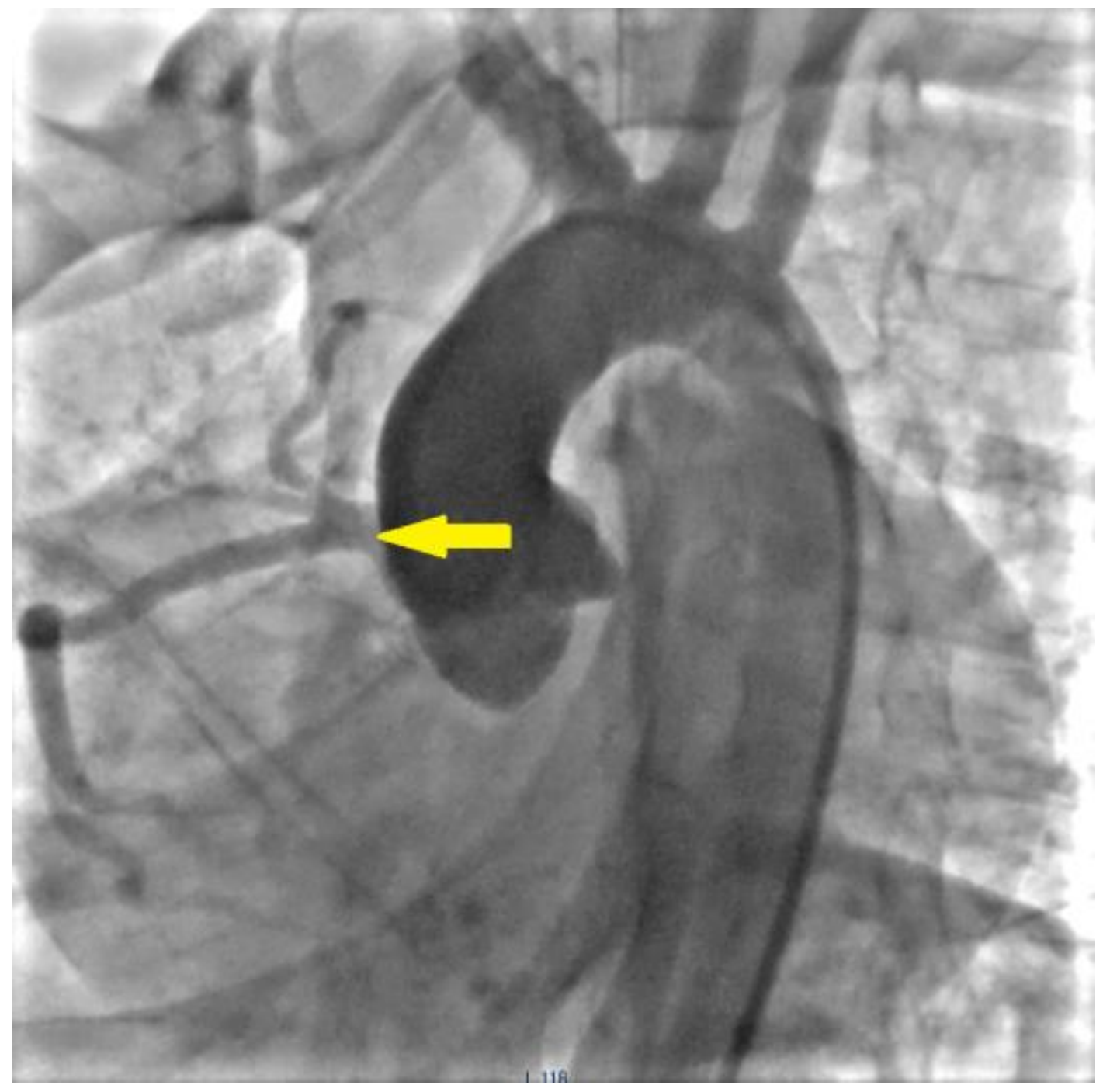

Figure 1

Aortography. Antero-posterior view showing wide right coronary artery (yellow arrow) with conal branch crossing right ventricular outlet tract. Absent left main coronary artery. 


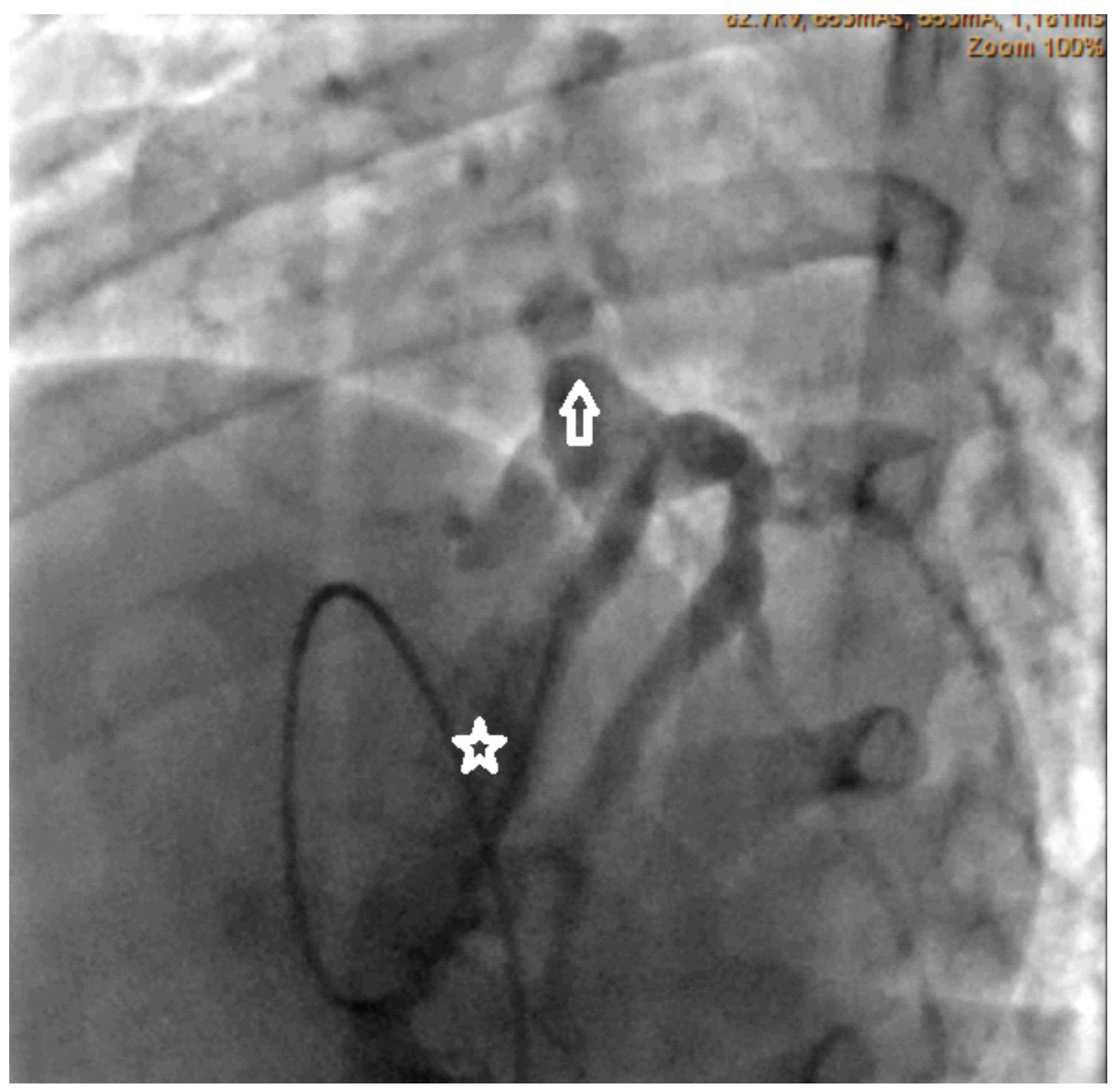

Figure 2

Selective fistula angiography (LAO 28 $8^{\circ}$, Caudal $\left.37^{\circ}\right)$. Long and wide fistula (white star). Atresia of the left coronary artery ostium (white arrow). 


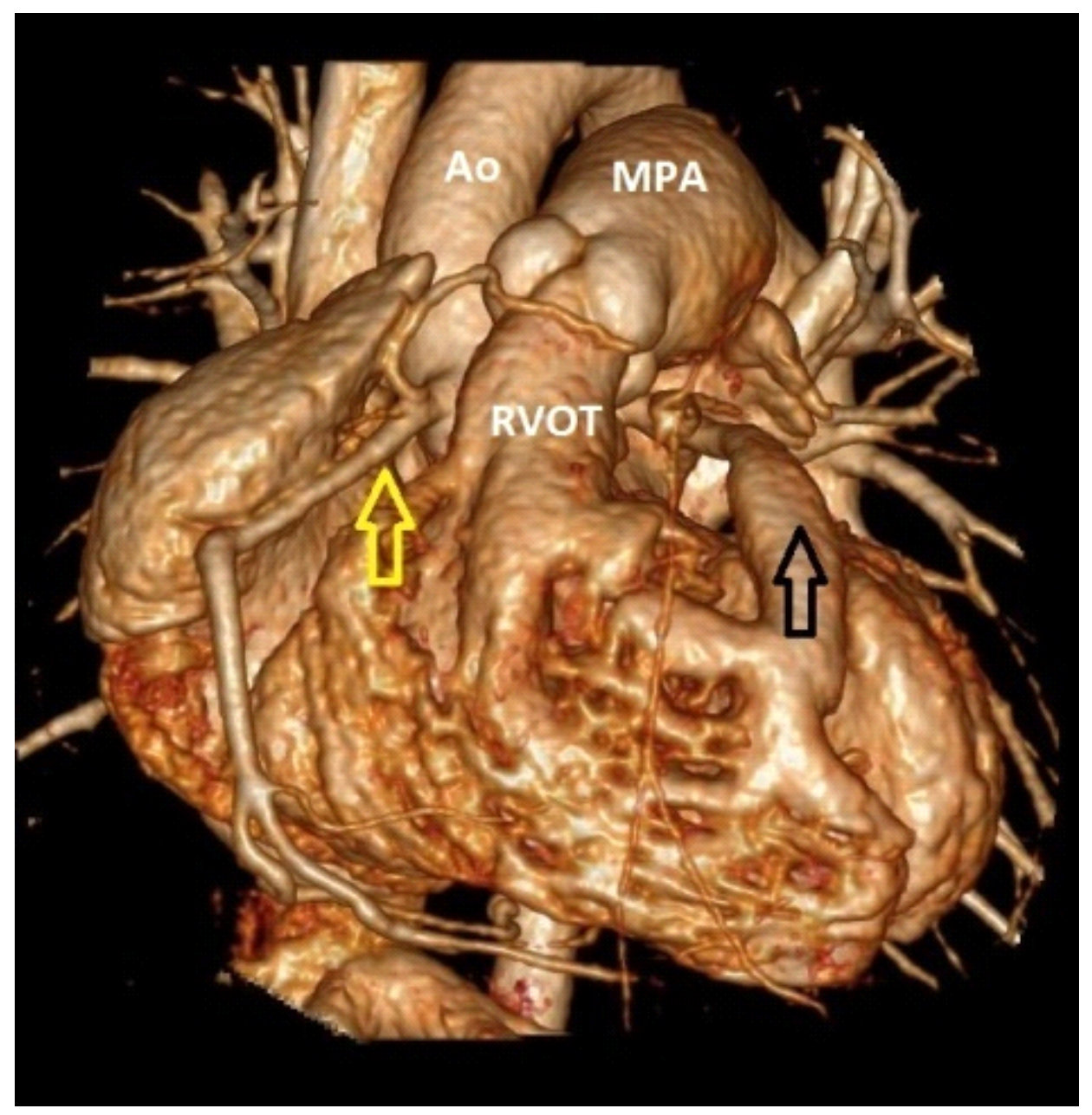

\section{Figure 3}

$3 \mathrm{D}$ rendered computed tomography. A wide fistula (black arrow) with multiple branches emerging from a hypertrophic right ventricle. Wide right coronary artery (yellow arrow).

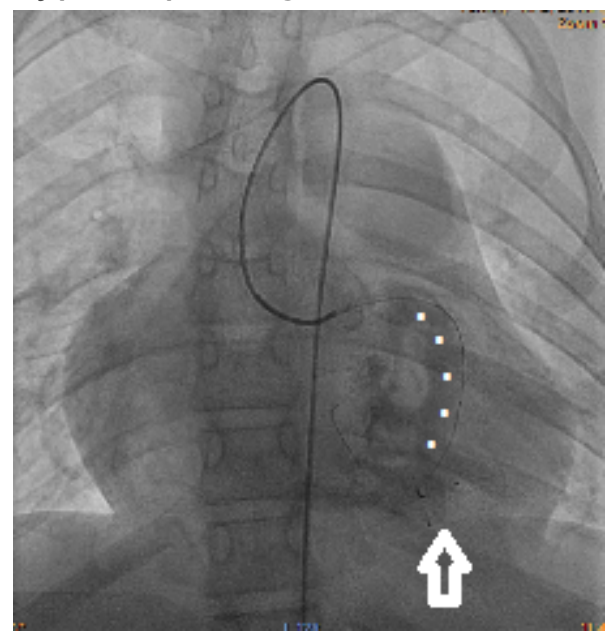

\section{Figure 4}

Selective left coronarography with patent fistula (white dots) and the steal phenomenon from the left coronary artery into the decompressed right ventricle. The occluder devices implanted during the 
operation (white arrow).

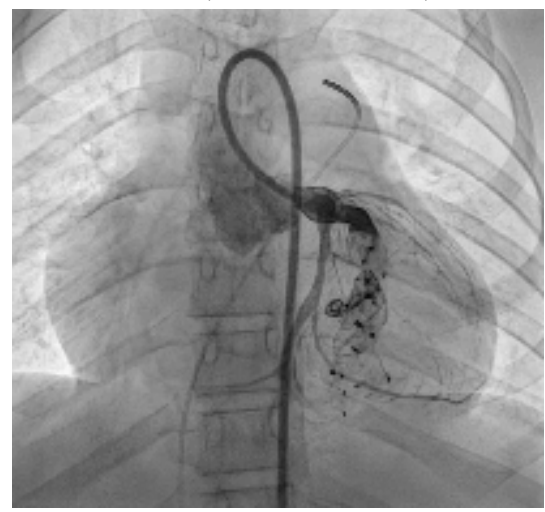

Figure 5

The fistula with multiple occluder devices and restored antegrade coronary flow.

\section{Supplementary Files}

This is a list of supplementary files associated with this preprint. Click to download.

- CAREchecklistEnglish2013.pdf

- Consent.jpg

- Video1.mp4

- Video2.mp4

- Video3.mp4

- Video4.mp4

- Video5.mp4 